\title{
Cantharidin and norcantharidin impair stemness of pancreatic cancer cells by repressing the $\beta$-catenin pathway and strengthen the cytotoxicity of gemcitabine and erlotinib
}

\author{
WEN-JIE WANG $^{1 *}$, MENG-YAO WU $^{1 *}$, MENG SHEN $^{1}$, QIAOMING ZHI ${ }^{2}$, ZE-YI LIU ${ }^{3,5}$, \\ FEI-RAN GONG ${ }^{4}, \mathrm{MIN}^{\mathrm{T} A \mathrm{O}^{1,6-8}}$ and WEI LI ${ }^{1,6}$ \\ Departments of ${ }^{1}$ Oncology, ${ }^{2}$ General Surgery, ${ }^{3}$ Respiratory Medicine, and ${ }^{4}$ Hematology, \\ The First Affiliated Hospital of Soochow University, Suzhou 215006; ${ }^{5}$ Institute of Respiratory Diseases, \\ ${ }^{6}$ PREMED Key Laboratory for Precision Medicine, ${ }^{7}$ Institute of Medical Biotechnology, Soochow University, \\ Suzhou 215021; ${ }^{8}$ Jiangsu Institute of Clinical Immunology, Suzhou 215006, P.R. China
}

Received July 2, 2015; Accepted August 20, 2015

DOI: 10.3892/ijo.2015.3156

\begin{abstract}
Increasing evidence suggests that tumors are composed of a heterogeneous cell population with a small subset of cancer stem cells (CSCs) that sustain tumor formation and growth, and are hypothesized to account for therapeutic resistance. Based on the expression of the surface markers CD44, CD24, and EPCAM, putative CSCs have also been identified in pancreatic cancers. It has been well established that aberrant activation of $\beta$-catenin signaling pathway may contribute to the maintenance of CSCs. Cantharidin is an active constituent of mylabris, a traditional Chinese medicine. In our previous studies, we demonstrated that cantharidin treatment induced phosphorylation of $\beta$-catenin, leading to repression on $\beta$-catenin pathway. Therefore, in the present study, we investigated whether cantharidin and its derivant, norcantharidin, could repress the stemness of pancreatic cancer cells through repression on $\beta$-catenin pathway. By using microarray and flow cytometry, we found that treatment with cantharidin and norcantharidin repressed the expression of CD44, CD24, and EPCAM at both mRNA and protein levels, leading to decreased $\mathrm{CD} 44^{+} / \mathrm{CD} 24^{+} / \mathrm{EPCAM}^{+}$
\end{abstract}

Correspondence to: Dr Wei Li or Dr Min Tao, Department of Oncology, The First Affiliated Hospital of Soochow University, Suzhou 215006, P.R. China

E-mail: liwei10@suda.edu.cn; dr_weili@163.com

E-mail: taomin@suda.edu.cn; mtao@medmail.com.cn

*Contributed equally

Abbreviations: $\mathrm{PP} 2 \mathrm{~A}$, protein phosphatase 2A; CSC, cancer stem cell; HGF, hepatocyte growth factor; MMP, matrix metalloproteinase; MAPK, mitogen-activated protein kinase; EGF, epidermal growth factor; E-FABP, epidermal fatty acid binding protein

Key words: pancreatic cancer, cancer stem cells, cantharidin, PP2A, $\beta$-catenin proportion, the putative pancreatic CSC subset. Pretreatment with the $\beta$-catenin pathway inhibitor FH535, attenuated the cantharidin- and norcantharidin-inducrd repression on CD44, CD24, and EPCAM, suggesting cantharidin and its derivant repressed stemness of pancreatic cancer cells in $\beta$-catenin pathway-dependent manner. Furthermore, cantharidin and norcantharidin strengthened the cytotoxicity of gemcitabine and erlotinib, two well established pharmacotherapeutics against pancreatic cancers, indicating cantharidin and norcantharidin could be promising candidates for reversing drug resistance in pancreatic cancers. In conclusion, we presently propose that cantharidin and norcantharidin hold their promise in pancreatic cancer therapy through repression on stemness and strengthening the cytotoxicity of the present therapeutics.

\section{Introduction}

Pancreatic cancer is one of the most lethal human cancers. The 1-year survival rate, for all stages of the cancer, is only $26 \%$ from the time of diagnosis, and the five-year survival rate is $<5 \%$ (1). These poor prognoses are mainly attributable to late diagnosis, and its resistance to current therapies. Despite enormous efforts in basic and clinical research in the fight against pancreatic cancer, there is still a huge discrepancy in treatment benefit between preclinical and clinical stages. Even when patients are able to undergo surgery at an early stage, they frequently suffer recurrence or metastasis (2-4). Therefore, new treatments against this aggressive neoplasm are urgently needed.

It has been well accepted that in tumors there is a subgroup of cancer cells, termed cancer stem cells (CSCs) (5). In the past few years, CSCs have been found in most types of hematopoietic and solid tumors including brain tumor, breast, head and neck, colon, lung, prostate, ovarian, and pancreatic cancers (5). CSCs have been proved to preserve the abilities of extensive proliferation, self-renewal, multi-lineage differentiation, and high tumorigenic potential (5). The critical role of pancreatic CSCs in regulating pancreatic cancer progression, metastasis, and drug resistance has since been confirmed $(6,7)$. Therefore, 
targeting CSCs could be a novel strategy for the treatment of pancreatic cancers.

Natural products and their derivatives have shown promising outcomes in cancer therapies. In our previous study, we demonstrated that cantharidin, the active constituent of Chinese blister beetle (8), inhibited growth and metastasis of pancreatic cancer cells (9-13), offering a potential role for cantharidin in the treatment of pancreatic cancer. Cantharidin acts as a potent and selective inhibitor of protein phosphatase 2A (PP2A) (14), a multimeric serine/threonine phosphatase. Inhibition of PP2A can result in phosphorylation of multiple substrates, including $\beta$-catenin, a key component of $\mathrm{WNT} / \beta$-catenin pathway. In our previous study, phosphorylation of $\beta$-catenin induced by PP2A inhibitors led to repression on $\mathrm{WNT} / \beta$-catenin pathway (12).

It has been well established that $\mathrm{WNT} / \beta$-catenin signaling pathway is crucial for normal stem cell self-renewal and tissue differentiation (15). Recent studies proposed that aberrant activation of $\mathrm{WNT} / \beta$-catenin signaling pathway may contribute to the maintenance of CSCs (16). Therefore, in the present study, we tried to verify whether cantharidin and norcantharidin could repress the stemness of pancreatic cancer cells through inhibition on $\beta$-catenin signaling pathway.

As CSCs are generally more resistant than other cancer cells to conventional anticancer therapeutics, we also tried to verify whether cantharidin and norcantharidin could strengthen the cytotoxicity of gemcitabine and erlotinib, two first line pharmacotherapeutics commonly used in the treatment of pancreatic cancers (17).

\section{Materials and methods}

Cell line and cultures. The human pancreatic cancer cell lines, PANC-1 and CFPAC-1, were purchased from the American Type Culture Collection (ATCC, VA, USA). Cells were maintained in Dulbecco's minimum essential medium (DMEM; Gibco, NY, USA) supplemented with $10 \%$ fetal calf serum (FCS; Hyclone, UT, USA), $100 \mathrm{U} / \mathrm{ml}$ penicillin, and $100 \mathrm{mg} / \mathrm{ml}$ streptomycin. The cultures were incubated at $37^{\circ} \mathrm{C}$ in a humidified atmosphere with $5 \% \mathrm{CO}_{2}$. Cells were passaged every 2-3 days to obtain exponential growth.

Reagents. Cantharidin was purchased from Enzo Life Sciences International (Plymouth Meeting, PA, USA). Norcantharidin (NCTD) was purchased from Sigma (St. Louis, MO, USA). FH535 was purchased from Millipore (Billerica, MA, USA).

MTT assay. Cellular growth was evaluated by MTT (3-[4,5dimethyltiazol-2-yl] 2,5-diphenyl-tetrazolium bromide) assay (9). Cells were seeded into 24-well tissue culture plates at $5 \times 10^{4}$ cells per well. After treatment, MTT (Sigma) was added to each well to a final concentration of $0.5 \mathrm{mg} / \mathrm{ml}$, followed by incubation at $37^{\circ} \mathrm{C}$ for $4 \mathrm{~h}$. The medium was then removed, and $600 \mu 1$ of dimethyl sulfoxide (DMSO) was added per well. As the PP2A inhibitor-treated cells became detached (18), the formazan in the medium was harvested by centrifugation at $10,000 \mathrm{rpm}$ for $10 \mathrm{~min}$, dissolved in $200 \mu \mathrm{l}$ of DMSO, and then returned to the original well. The absorbance of total $800 \mu 1$ formazan dissolved DMSO in each well was measured at $490 \mathrm{~nm}$ using a microplate ELISA reader (Bio-Rad
Laboratories, CA, USA). The relative cell viability was calculated as follows: relative cell viability $=$ (mean experimental absorbance/mean control absorbance) x $100 \%$.

Plate clone formation assay. The cells were seeded at a density of 200 cells/well in 24-well plates and treated $12 \mathrm{~h}$ later. After 15 days, the cells were stained with $1 \%$ methylrosanilinium chloride and the numbers of visible colonies were counted. The relative clone formation ability was calculated as relative clone formation ability = (mean experimental clone number/ mean control clone number) x $100 \%$

Microarray assay. Sample preparation and processing procedure were performed as described in detail in the Agilent GeneChip Expression Analysis Manual (Santa Clara, CA, USA). Differentially expressed genes were screened using Agilent 44K human whole-genome oligonucleotide microarrays. The selection criterion was defined as a $>1.5$-fold difference in the level of expression (difference in upregulated expression $>1.5$-fold, and difference in downregulated expression $<0.5$-fold). Hierarchical clustering of samples was done by average linkage algorithm using TIGR MultiExperiment Viewer (The Institute for Genomic Research, Rockville, MD, USA).

Protein expression evaluation. The protein expression levels of CD24, CD44 and EPCAM in pancreatic cancer cells was measured by flow cytometry. Following treatment, the cells were harvested, fixed with $4 \%$ paraformaldehyde and permeabilized using $0.1 \%$ Triton X-100. After washing with PBS three times, cells were incubated with anti-CD24 (FITC-conjugated, Santa Cruz), anti-CD44 (PE-conjugated, Santa Cruz), and antiEPCAM (PerCP-cy5.5-conjugated, Santa Cruz) antibodies, respectively, for $30 \mathrm{~min}$ at $4{ }^{\circ} \mathrm{C}$. Subsequently, the cells were analyzed using a Beckman Coulter FC500 dual-laser fivecolor flow cytometer (Beckman Coulter).

Pancreatic cancer cell stemness evaluation. Cells were harvested, washed twice with $2 \% \mathrm{FBS} / \mathrm{PBS}$ solution, and resuspended in $100 \mu \mathrm{l}$ of $2 \% \mathrm{FBS} / \mathrm{PBS}$ before incubating with anti-CD24 (FITC-conjugated), anti-CD44 (PE-conjugated), and anti-EPCAM (PerCP-cy5.5-conjugated) antibodies for $30 \mathrm{~min}$ at $4^{\circ} \mathrm{C}$. Cells were then washed twice with $2 \% \mathrm{FBS} / \mathrm{PBS}$ solution, and resuspended in $500 \mu \mathrm{l}$ of $2 \% \mathrm{FBS} / \mathrm{PBS}$ prior to reading on a Beckman Coulter FC500 dual-laser five-color flow cytometer (Beckman Coulter).

Real-time PCR. Total RNA was extracted using TRIzol reagent (Invitrogen, CA, USA) according to the manufacturer's protocol. After spectrophotometric quantification, $1 \mu \mathrm{g}$ total RNA in a final volume of $20 \mu \mathrm{l}$ was used for reverse transcription with PrimeScript RT Reagent kit (Takara, Otsu, Shiga, Japan) according to the manufacturer's protocol. Aliquots of cDNA corresponding to equal amounts of RNA were used for quantification of mRNA by real-time PCR using the LightCycler 96 Real-time Quantitative PCR Detection system (Roche, Indianapolis, IN, USA). The reaction system $(25 \mu \mathrm{l})$ contained the corresponding cDNA, forward and reverse primers, and SYBR Green PCR master mix (Roche). All data were analyzed using B2M gene expression as an internal stan- 
A

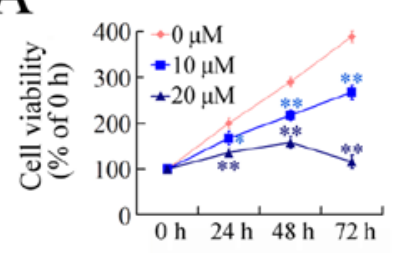

B

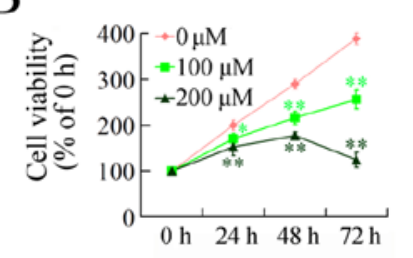

C

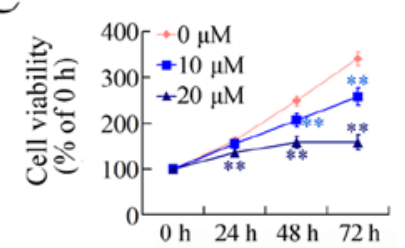

D

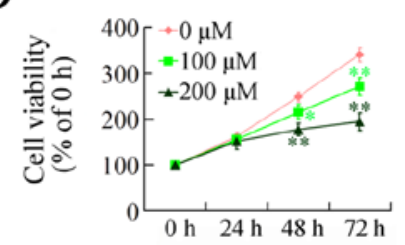

E

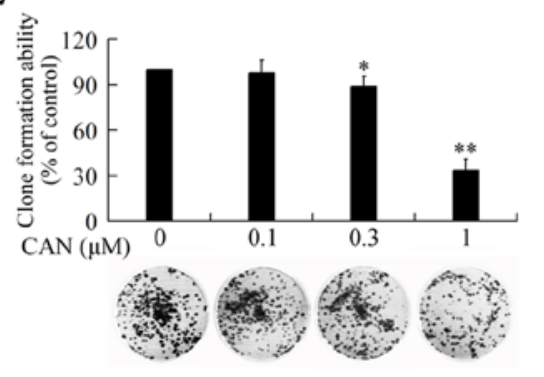

F

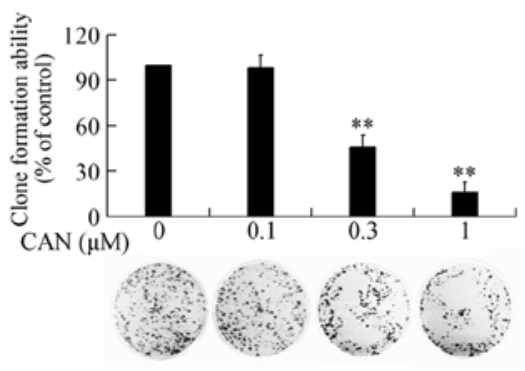

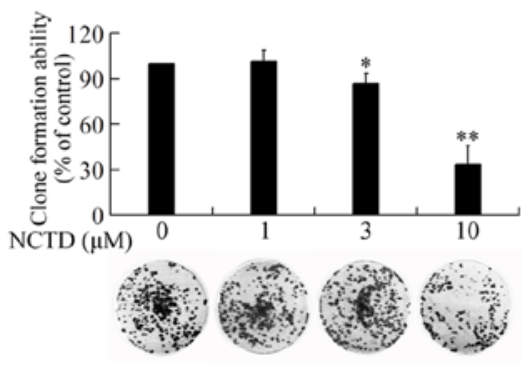

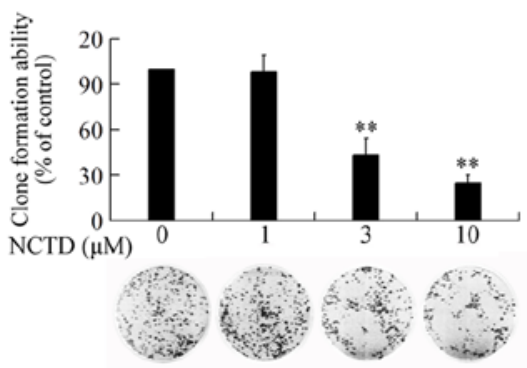

G
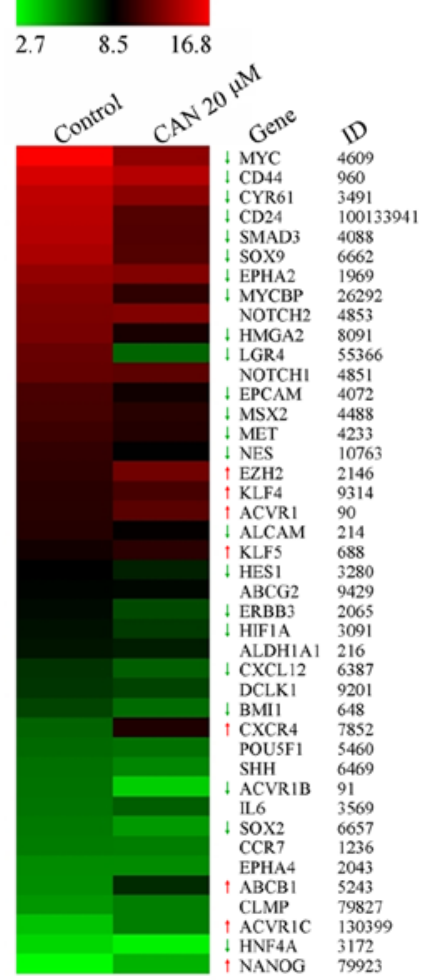

Figure 1. Repression on pancreatic cancer cell growth by cantharidin and norcantharidin. (A and B) Exposure to various concentrations of cantharidin (A) and norcantharidin (B) resulted in a dose- and time-dependent growth inhibition in PANC-1 cells. (C and D) Dose- and time-dependent growth inhibition in CFPAC-1 cells by cantharidin (C) and norcantharidin (D). (E) Cantharidin (CAN) and norcantharidin (NCTD) treatment inhibited the clone formation ability of PANC-1 cells in a dose-dependent manner. (F) Cantharidin (CAN) and norcantharidin (NCTD) treatment dose-dependently inhibited the clone formation ability of CFPAC-1 cells. $\mathrm{P}<0.05 ;{ }^{* *} \mathrm{P}<0.01$ indicates significant differences from the respective control groups. (G) llustration of results of the microarrays. Up and down arrows indicate the gene expression significantly upregulated or downregulated, respectively, by 1.5 -fold.

dard. The specific primers were as follows: i) CD24, forward, 5'-CAGGGCAATGATGAATGAGAAT-3', reverse, 5'-CCT GGGCGACAAAGTGAGA-3', product, 233 bp; ii) CD44, forward, 5'-GTGATGGCACCCGCTATGTC-3', reverse, 5'-AAC CTCCTGAAGTGCTGCTCC-3', product, 129 bp; iii) EPCAM, forward, 5'-TAATCGTCAATGCCAGTGTACTTC-3', reverse, 5'-GCCATTCATTTCTGCCTTCAT-3', product, 100 bp; iv) B2M, forward, 5'-TCAAGAAGGTGGTGAAGCAG-3', reverse, 5'-AAGGTGGAGGAGTGGGTGTC-3', product, $112 \mathrm{bp}$.

Statistical analysis. Each experiment was performed a minimum of three times. Results were expressed as the mean value \pm standard deviation (SD). Statistical analysis was performed by unpaired Student's t-test. The correlations between microarray assays were analyzed using Spearman's rank correlation analysis. A P-value $<0.05$ was considered significant.

\section{Results}

Cantharidin and norcantharidin repressed pancreatic cancer cell growth and downregulated stemness markers. Dose- and time-dependent repression on pancreatic cancer cell growth by cantharidin and norcantharidin was firstly confirmed by MTT assay (Fig. 1A-D). To investigate the cytotoxicity of long-term exposure of cantharidin and norcantharidin, PANC-1 and CFPAC-1 cells were treated with cantharidin and norcantharidin at low doses and cell growth was evaluated by using plate clone formation assay. As shown in Fig. 1E and F, both cantharidin and norcantharidin presented significant dose-dependent inhibition on the clone formation ability of pancreatic cancer cells. As the clone formation ability often correlated with stemness (19), we further investigated whether cantharidin and norcantharidin could affect the stemness of pancreatic cancer cells. Expressions of stem cell related genes were evaluated by microarray assay. As shown in Fig. 1G, 

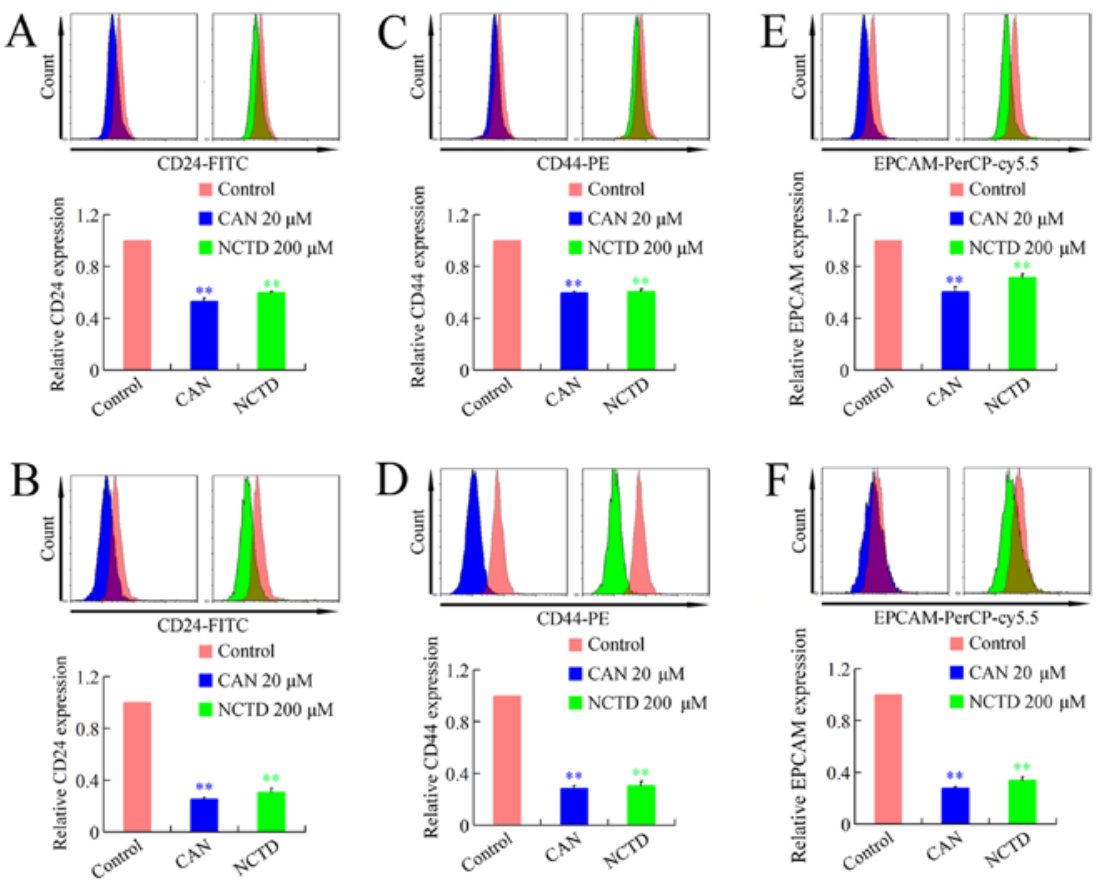

Figure 2. Cantharidin and norcantharidin repress protein expression of CD24, CD44 and EPCAM. (A and B) Protein expression of CD24 in PANC-1 (A) and CFPAC-1 (B) cells after treatment with cantharidin (CAN) and norcantharidin (NCTD) for $24 \mathrm{~h}$. (C and D) Protein expression of CD44 in PANC-1 (C) and CFPAC-1 (D) cells after treatment with cantharidin (CAN) and norcantharidin (NCTD) for $24 \mathrm{~h}$. (E and F) Protein expression of EPCAM in PANC-1 (E) and CFPAC-1 (F) cells after treatment with cantharidin (CAN) and norcantharidin (NCTD) for $24 \mathrm{~h} .{ }^{* *} \mathrm{P}<0.01$ indicates significant differences from the respective control groups.

A
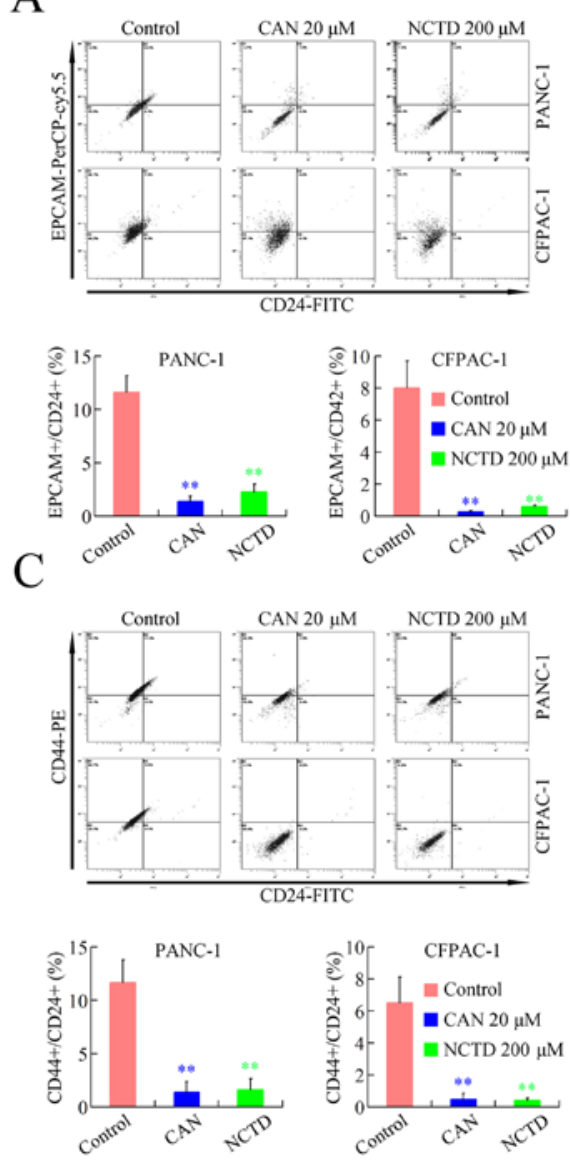

B

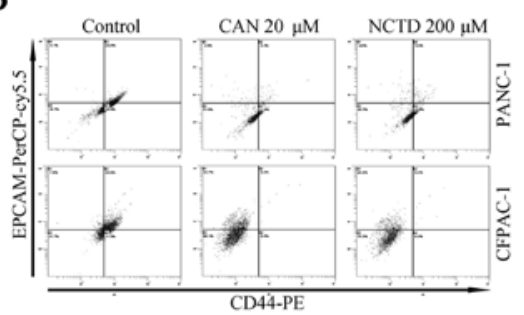

$\mathrm{D}$
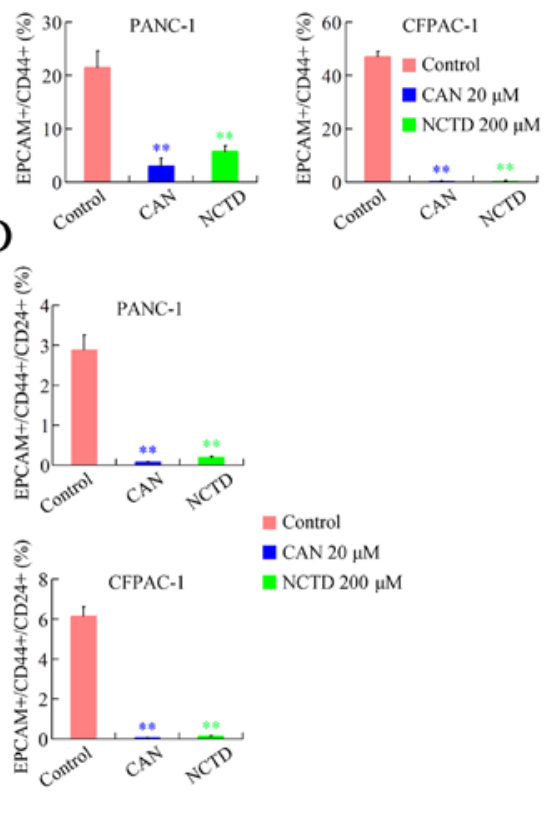

Figure 3. Cantharidin and norcantharidin decreased proportion of pancreatic CSCs. (A) Cantharidin (CAN) and norcantharidin (NCTD) downregulated $\mathrm{CD}_{24} / \mathrm{EPCAM}^{+}$subset. (B) Cantharidin (CAN) and norcantharidin (NCTD) decreased CD44 $/ \mathrm{EPCAM}^{+}$population. (C) Cantharidin (CAN) and norcantharidin (NCTD) eradicated the $\mathrm{CD} 24^{+} / \mathrm{CD} 44^{+}$subgroup. (D) Cantharidin (CAN) and norcantharidin (NCTD) abolished CD $24^{+} / \mathrm{CD}^{2} 4^{+} / \mathrm{EPCAM}^{+}$proportion ${ }^{* *} \mathrm{P}<0.01$ indicates significant differences from the respective control groups. 
A
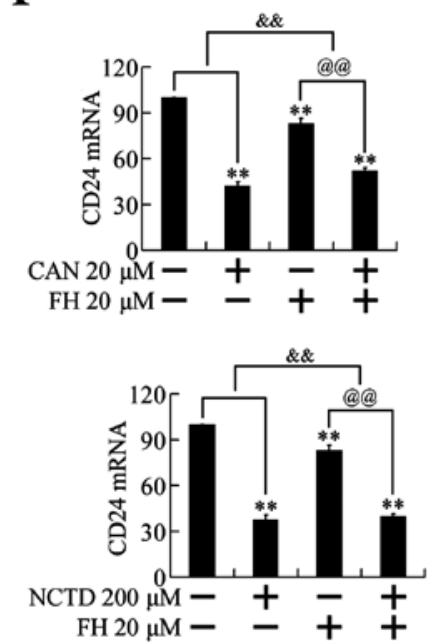

C

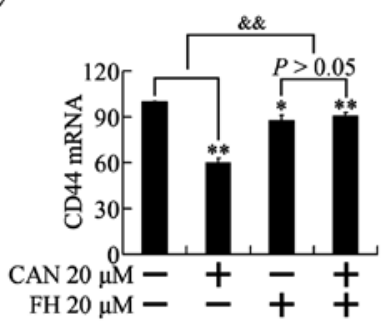

E

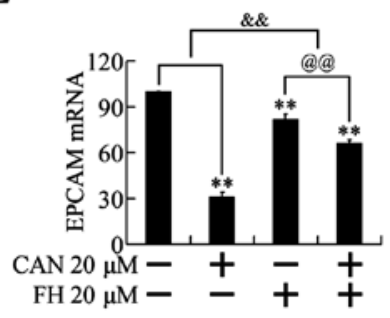

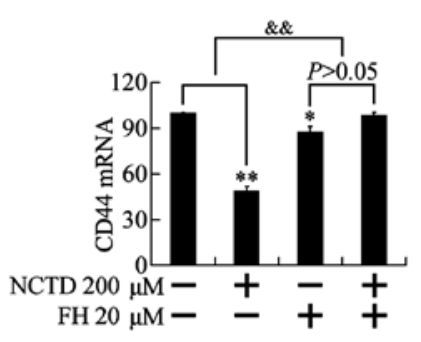
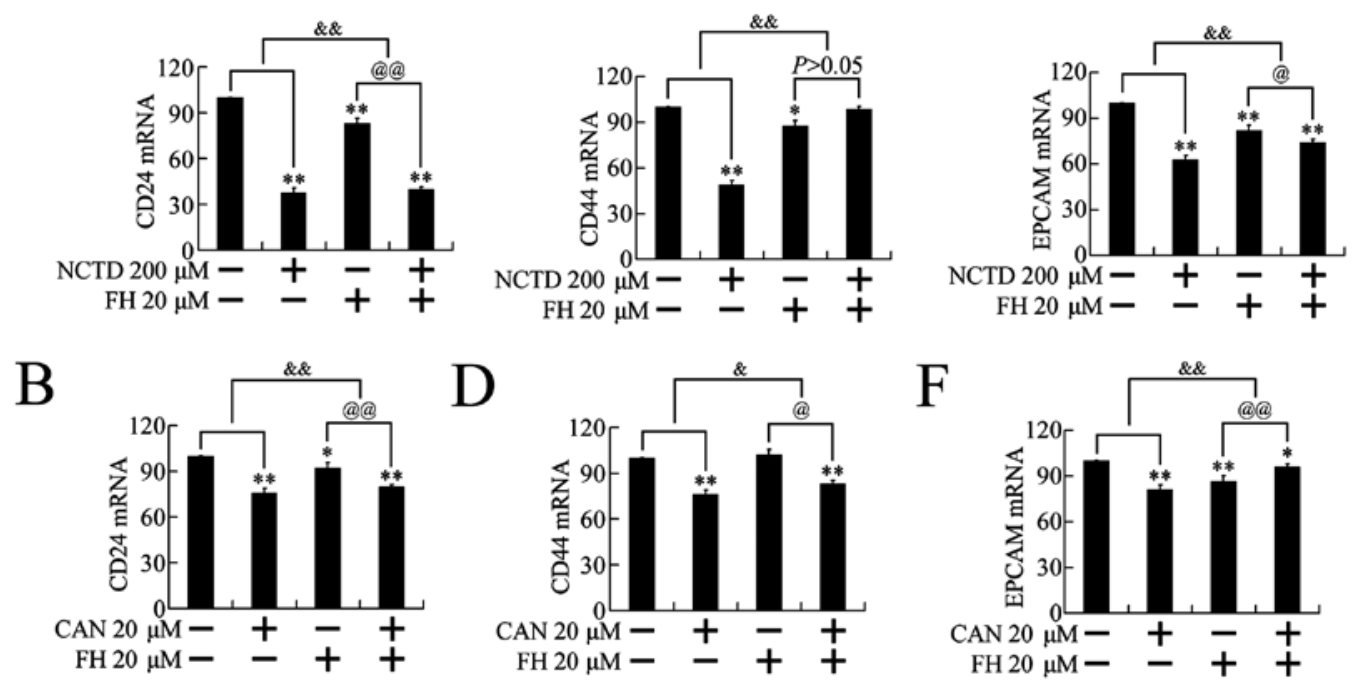

D

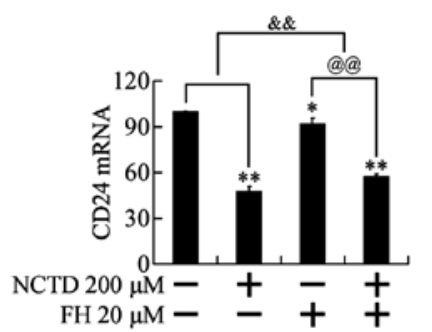

F

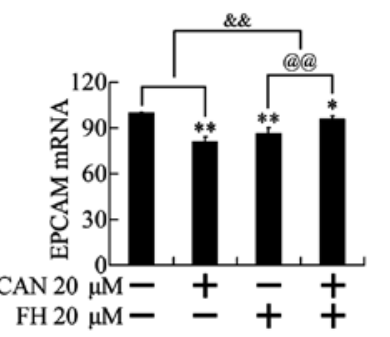

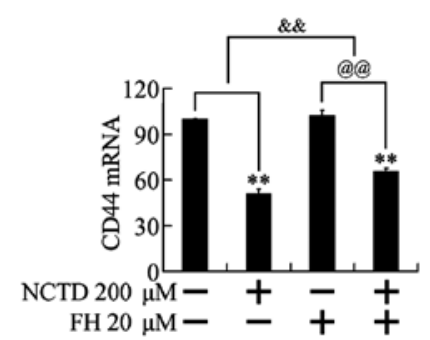

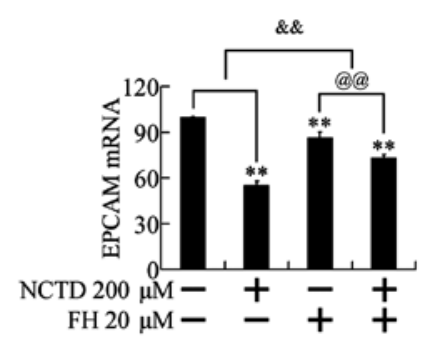

Figure 4. Cantharidin and norcantharidin repress expression of CD24, CD44 and EPCAM in a $\beta$-catenin pathway-dependent manner. (A and B) Pretreatment with FH535 (FH) impaired the repression on CD24 expression by cantharidin (CAN) and norcantharidin (NCTD) in PANC-1 (A) and CFPAC-1 (B) cells. (C and D) Pretreatment with FH535 (FH) impaired the repression on CD44 expression by cantharidin (CAN) and norcantharidin (NCTD) in PANC-1 (C) and CFPAC-1 (D) cells. (E and F) Pretreatment with FH535 (FH) impaired the repression on EPCAM expression by cantharidin (CAN) and norcantharidin (NCTD) in PANC-1 (E) and CFPAC-1 (F) cells. ${ }^{* *} \mathrm{P}<0.05,{ }^{* *} \mathrm{P}<0.01$ vs. respective control groups; ${ }^{\circledR} \mathrm{P}<0.05,{ }^{\circledR}{ }^{\circledR} \mathrm{P}<0.01$ vs. FH535 group; ${ }^{\&} \mathrm{P}<0.05,{ }^{\&} \mathrm{P}<0.01$ induction between groups.

although 8 genes (EZH2, KLF4, ACVR1, KLF5, CXCR4, ABCB1, ACVR1C and NANOG) were upregulated, expressions of 23 genes (MYC, CD44, CYR61, CD24, SMAD3, SOX9, EPHA2, MYCBP, HMGA2, LGR4, EPCAM, MSX2, MET, NES, ALCAM, HES1, ERBB3, HIF1A, CXCL12, BMI1, ACVR1B, SOX2 and HNF4A) were repressed, suggesting stemness of pancreatic cancer cells was repressed by cantharidin treatment.

Cantharidin and norcantharidin repressed CD24, CD44 and EPCAM expression at protein levels. CD24, CD44 and EPCAM are the well accepted pancreatic CSC markers (20). As microarray assay indicated repressed mRNA expression of these three markers, we further confirmed the downregulation of CD24, CD44 and EPCAM at protein level by using flow cytometry. As shown in Fig. 2, expression of the three markers was downregulated, confirming the repressed stem- ness of pancreatic cancer cells upon treatment of cantharidin and norcantharidin.

Cantharidin and norcantharidin repress $C D 24^{+} / C D 44^{+} /$ EPCAM $M^{+}$proportion in pancreatic cancer cells. As expression of CD24, CD44 and EPCAM was repressed by cantharidin and norcantharidin, we further used flow cytometry to evaluate the positivity of CD24, CD44 and EPCAM on the surface of pancreatic cancer cells. As shown in Fig. 3A-C, flow cytometry by using pairwise coupling of these three markers suggested decreased distributions of all three markers on the surface of pancreatic cancer cells after treatment with cantharidin and norcantharidin. Analysis by using the triplet combination of CD24, CD44 and EPCAM indentified 2.89( \pm 0.37$) \%$ and $6.14( \pm 0.47) \% \mathrm{CD}^{2} 4^{+} / \mathrm{CD} 44^{+} / \mathrm{EPCAM}^{+}$cells in PANC-1 and CFPAC-1 cells, respectively. After treatment with cantharidin for $24 \mathrm{~h}$, the proportion dropped to $0.07( \pm 0.03) \%$ and 
A
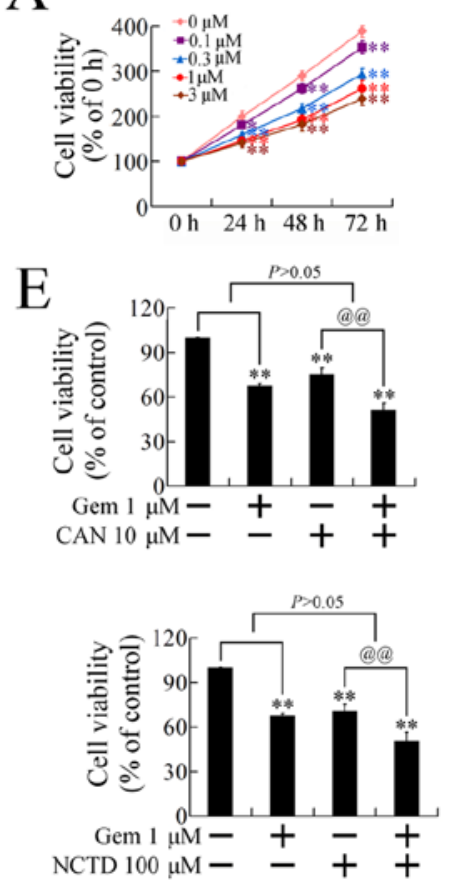

B
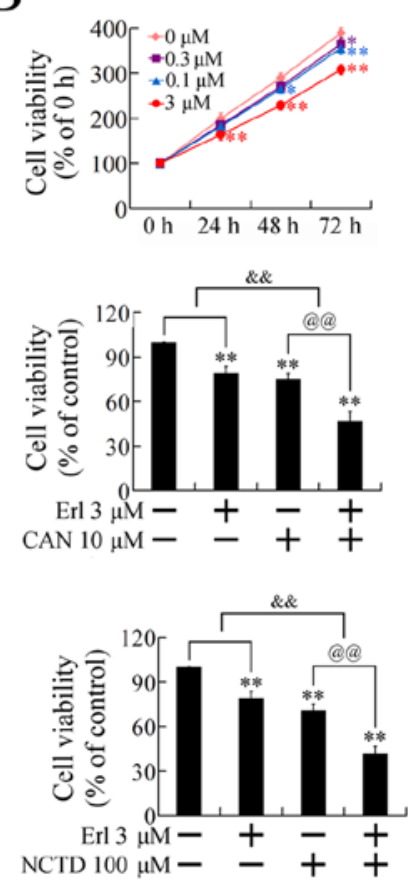

$\mathrm{C}$

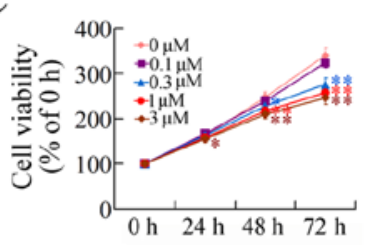

$\mathrm{F}$
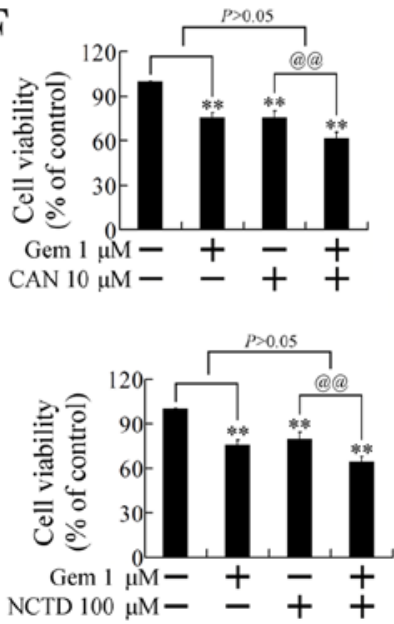

$\mathrm{D}$
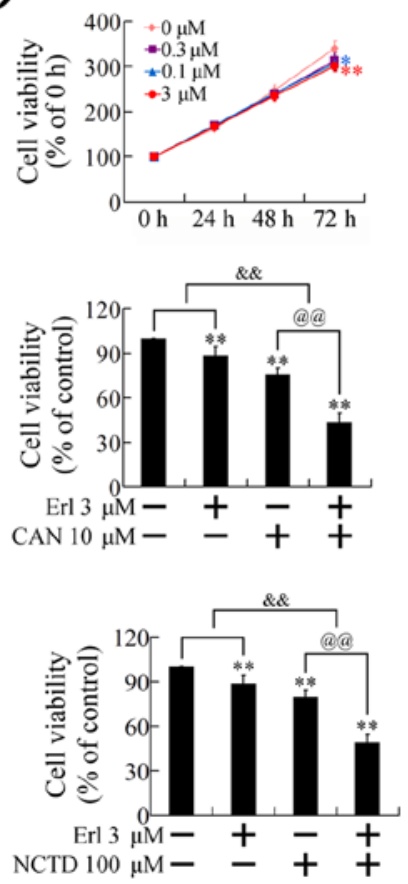

Figure 5. Cantharidin and norcantharidin strengthen cytotoxicity of erlotinib after short-term exposure. (A and B) Exposure to various concentrations of gemcitabine (A) and erlotinib (B) resulted in a dose- and time-dependent growth inhibition in PANC-1 cells. (C and D) Dose- and time-dependent growth inhibition in CFPAC-1 cells by gemcitabine (C) and erlotinib (D). (E and F) PANC-1 (E) and CFPAC-1 (F) cells were co-treated by cantharidin (CAN) or norcantharidin (NCTD) with gemcitabine (Gem) or erlotinib (Erl) for $72 \mathrm{~h} .{ }^{* *} \mathrm{P}<0.01$ vs. respective control groups; ${ }^{@} \mathrm{P}<0.01 \mathrm{vs}$. cantharidin $(\mathrm{CAN})$ or norcantharidin $(\mathrm{NCTD})$ group; $\& \& \mathrm{P}<0.01$ induction between groups.

$0.05( \pm 0.03) \%$ respectively. Norcantharidin treatment also resulted in decreased $\mathrm{CD} 24^{+} / \mathrm{CD} 44^{+} / \mathrm{EPCAM}^{+}$population to $0.12( \pm 0.03) \%$ and $0.13( \pm 0.03) \%$ in PANC- 1 and CFPAC- 1 cells, respectively.

Cantharidin and norcantharidin repress expression of $C D 24, C D 44$ and EPCAM $\beta$-catenin pathway-dependently. Previous studied indicated that $\beta$-catenin pathway is essential for maintaining stemness of CSCs, (16) and we previously demonstrated that cantharidin is able to block the $\beta$-catenin pathway (12). To find out whether $\beta$-catenin pathway was involved in the repressed stemness by cantharidin and norcantharidin, pancreatic cancer cells were pretreated with the classical $\beta$-catenin pathway inhibitor FH535, and expression of CD24, CD44 and EPCAM were then tested after treatment with cantharidin and norcantharidin. As shown in Fig. 4, downregulation of CD24, CD44 and EPCAM was attenuated by FH535 pretreatment in each, suggesting cantharidin and norcantharidin repressed stemness of pancreatic cancer cells $\beta$-catenin pathway dependently.

Cantharidin and norcantharidin strengthen cytotoxicity of gemcitabine and erlotinib. Gemcitabine and erlotinib are first line pharmacotherapeutics against pancreatic cancer. However, all patients receive these agents will develop resistence (17). As CSCs are responsible for the relative resistance of the tumor to systemic chemotherapy and radiation (5), and cantharidin and norcantharidin downregulated stemness of pancreatic cancer cells, we then investigate whether cantharidin and norcantharidin could strengthen the cytotoxicity of gemcitabine and erlotinib.
Dose- and time-dependent repression on pancreatic cancer cell growth by gemcitabine and erlotinib was first confirmed by MTT assay (Fig. 5A-D). Then, co-treatment of cantharidin or norcantharidin with gemcitabine or erlotinib was performed. As shown in Fig. 5E and F, co-treatment of cantharidin or norcantharidin with gemcitabine had no synthetic effect. However, cantharidin and norcantharidin significantly strengthened cytotoxicity of erlotinib.

We then performed plate clone formation assay, and evaluated whether cantharidin and norcantharidin could strengthen cytotoxicity of long-term exposure of gemcitabine and erlotinib at low doses. Dose-dependent repression on clone formation ability by gemcitabine and erlotinib was confirmed (Fig. 6A-D). Then, co-treatment of cantharidin or norcantharidin with gemcitabine or erlotinib was performed. As shown in Fig. 6E-H, cantharidin and norcantharidin significantly strengthened cytotoxicity of both gemcitabine and erlotinib, suggesting a potential of combination of cantharidin or norcantharidin with pharmacotherapeutics against pancreatic cancer.

\section{Discussion}

Pancreatic cancer is the fourth leading cause of cancer related deaths in Western countries (21). Reasons for the frustrating effort to find effective therapies could be due to the existence of a select population of cancer cells, termed cancer stem cells (CSCs) (5). There is increasing evidence proving that pancreatic cancer is a CSC-driven disease. Isolation and characterization of pancreatic CSCs reveal that these tumor-initiating cells share important molecular pathways seen in other solid-organ 
A

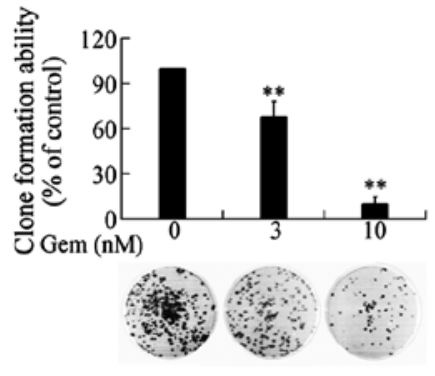

C

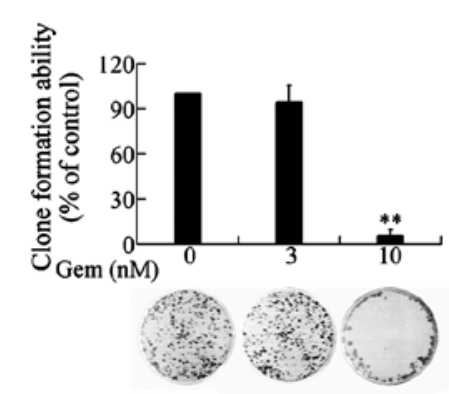

B

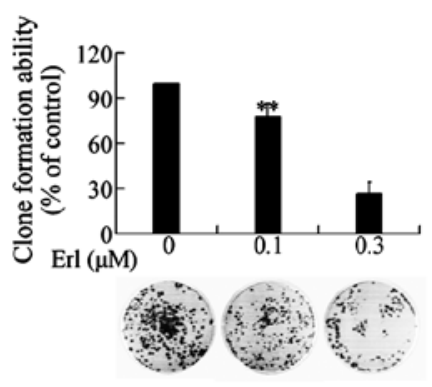

D

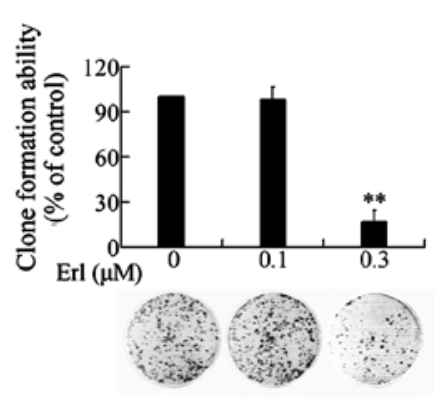

F

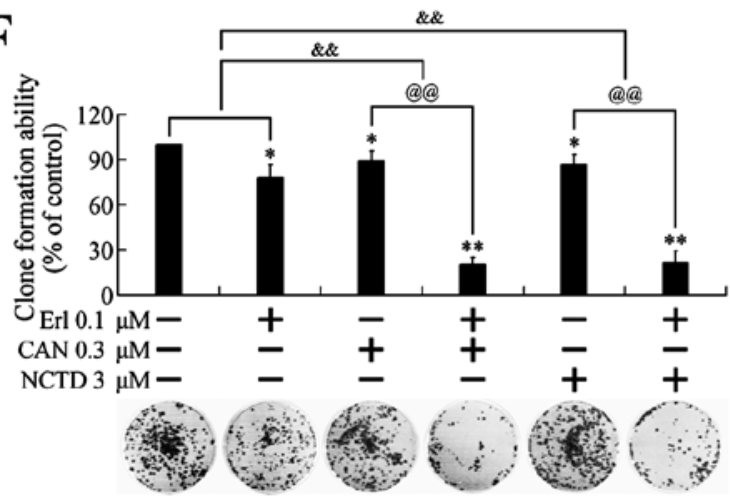

G

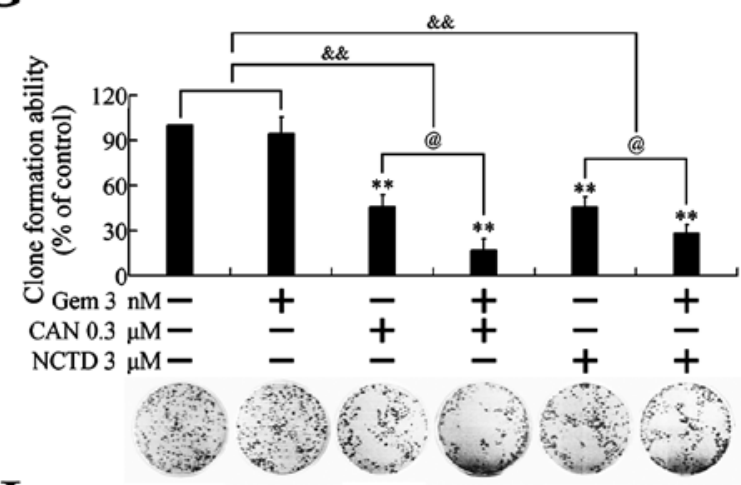

E

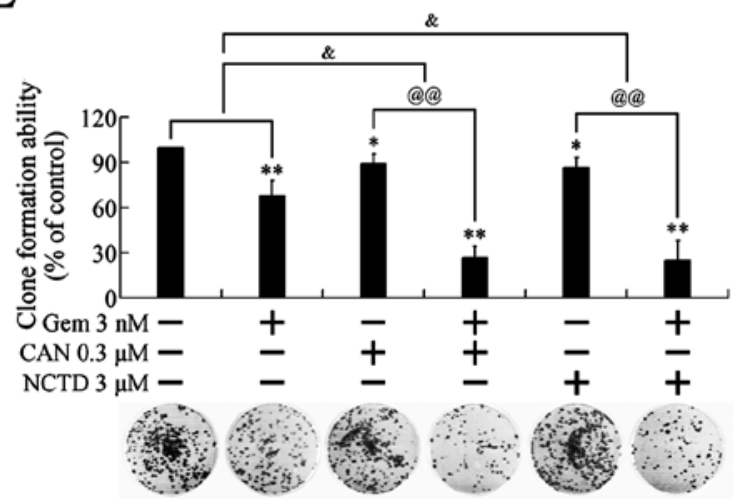

$\mathrm{H}$

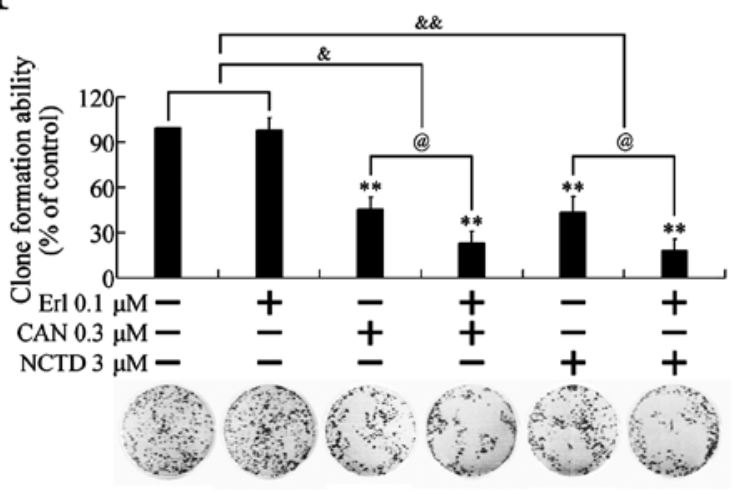

Figure 6. Cantharidin and norcantharidin strengthen cytotoxicity of gemcitabine and erlotinib after long-term exposure. (A and B) Gemcitabine (Gem) (A) and erlotinib (Erl) (B) treatment inhibited the clone formation ability of PANC-1 cells in a dose-dependent manner. (C and D) Gemcitabine (Gem) (C) and erlotinib (Erl) (D) treatment inhibited the clone formation ability of CFPAC-1 cells in a dose-dependent manner. (E and F) PANC-1 cells were co-treated by cantharidin (CAN) or norcantharidin (NCTD) with gemcitabine (Gem) (E) or erlotinib (Erl) (F) for 15 days. (G and H) CFPAC-1 cells were co-treated by cantharidin (CAN) or norcantharidin (NCTD) with gemcitabine $(\mathrm{Gem})(\mathrm{G})$ or erlotinib (Erl) $(\mathrm{H})$ for 15 days. ${ }^{* *} \mathrm{P}<0.01 \mathrm{vs}$. respective control groups; ${ }^{\circledR}{ }^{\circledR} \mathrm{P}<0.01$ vs. cantharidin (CAN) or norcantharidin (NCTD) group; ${ }^{\&} \mathrm{P}<0.01$ induction between groups.

CSCs (22). The deregulation of the pathway of self-renewal and differentiation in CSCs resulted in unlimited self-renewal and a subsequent excess of CSCs. In addition, CSCs have aberrant differentiation programs that generate progenitor tumor cells, which then proliferate to form the bulk of the tumor (23). CSCs have been found to be resistant to conventional cancer therapies including radiotherapy and chemotherapy. In addition, these cells can also escape the cytotoxic action of the host immune cells (24). Moreover, CSCs show their high propensity of invasiveness and metastasis (5). These features of CSCs could cause cancer recurrence after eliminating most of the cancer cells by conventional therapies. Thus, the presence of CSCs may explain how pancreatic cancer cells can re-grow even when anticancer treatment destroys tumor cells and shrinks the tumor size. Therefore, it is postulated that by developing strategies targeting CSCs can solve the problem of cancer recurrence and metastasis. It is important to note that therapeutics that eliminate the CSCs within a tumor may bring little or no immediate reduction in tumor size. However, tumor growth is not sustainable without CSCs to replenish the bulk population and the tumor will eventually degenerate as bulk tumor cells are depleted. Therefore it is of paramount importance to develop targeted therapies, which eliminate CSC, thereby destroying the sole source for new tumor cells (25).

The first identification of CSCs was reported by Bonnet in acute myeloid leukemia (26). Then, CSCs were identified in 
other cancers, including pancreatic cancer (20). Markers that have been utilized to identify pancreatic CSCs include CD24, CD44, EPCAM (a synonym for ESA, which was one of the CSC markers described in the original article of Li et al) (20), c-Met (27), CD133 (28), aldehyde dehydrogenase (ALDH) (28), and Hoechst dye exclusion (side population) (29).

CD24 is a heavily glycosylated protein, which was originally described as heat stable B cell-associated antigen. It is thought to be able to facilitate metastasis of tumor cells through binding to P-selectin (30).

CD44 overexpression in tumors has been shown to be correlated with invasiveness, metastasis and poor prognosis in various human tumors $(31,32)$. CD44 participates in cell survival and proliferation by harboring chemokines and growth factors, such as HGF (hepatocyte growth factor). CD44 also plays a role in angiogenesis and invasion via MMP (matrix metalloproteinase) binding (30). CD44 mediates matrix formation, which is crucial for the settlement and growth at a secondary site, whereas apoptosis resistance of CD $44^{+}$cells supports the efficacy of metastasis formation (33). Through interaction with integrins such as VLA-4, CD44 is able to activate the MAPK (mitogen-activated protein kinase) pathway. Finally, integrin activation may lead to activation of WNT/ $\beta$-catenin signaling pathway, which has been proven to be associated with maintaining stemness of CSCs $(30,34)$. In human pancreatic cancer samples, CD44 expression was correlated with histologic grade and the patients with CD44 tumors showed poor prognosis (23).

The cell adhesion molecule EPCAM is a type I transmembrane molecule with an EGF (epidermal growth factor)-like domain, followed by a thyroglobin repeat domain (35), a cysteine poor region, a transmembrane domain and a short cytoplasmic tail (36). EPCAM is thought to support metastasis formation (30). Previous investigation reported that modulation of cadherin-mediated cell-cell interactions by EPCAM could be a possible functional involvement of this molecule in tumor progression (37). Besides, EPCAM has been shown to be involved in signal transduction and to support cell motility $(38,39)$. Overexpression of EPCAM can also induce upregulation of the oncogenic c-myc and support cell proliferation via upregulated synthesis of cyclin A and E (40,41). Finally, like CD44, EPCAM also contributes in the activation of the stemness-preserving WNT/ $\beta$-catenin signaling pathway (42).

Combination, but not single marker, has been applied to the identification of pancreatic CSCs. By FACS analysis, Li et al were the first to isolate the $\mathrm{CD} 44^{+} / \mathrm{CD} 24^{+} / \mathrm{EPCAM}^{+}$ pancreatic CSCs from pancreatic cancer tissue. These CD44 ${ }^{+} /$ $\mathrm{CD}_{2} 4^{+} / \mathrm{EPCAM}^{+}$cells showed stem cell properties including self-renewal, the ability to produce differentiated progeny, and the increased expression of sonic hedgehog (20). The $\mathrm{CD}_{4} 4^{+} / \mathrm{CD} 44^{+} / \mathrm{EPCAM}^{+}$cells had a 100 -fold increased tumorigenic potential compared to marker-negative cancer cells. In an animal study, $50 \%$ of animals injected with as few as 100 $\mathrm{CD} 44^{+} / \mathrm{CD} 24^{+} / \mathrm{EPCAM}^{+}$cells formed tumors that were histologically indistinguishable from the original pancreatic cancer (20). Similar results were shown by follow-up studies. CD $44^{+} /$ $\mathrm{CD} 24^{+}$have a significantly higher possibility for colony formation in vitro (43), and are more resistant to irradiation (43). The characteristics of $\mathrm{CD} 44^{+} / \mathrm{CD} 24^{+} / \mathrm{EPCAM}^{+}$cells in clinical specimens of pancreatic cancer using immunohistochemical presented correlationship between CD44/CD24/EPCAM expression and poor glandular differentiation as well as high proliferation (44). Survival analysis showed that CD $44^{+} / \mathrm{CD} 24^{+}$ expression appeared to be correlated with poor prognosis (44). Thus, investigators have suggested that the subpopulation of pancreatic cancer cells showing CD $44^{+} / \mathrm{CD} 24^{+} / \mathrm{EPCAM}^{+}$had stem cell-like properties of self-renewal and the ability to produce differentiated progeny (23). In addition, CD44, CD24, and EPCAM are now widely used for the identification of pancreatic cancer stem cells $(28,44-47)$. In the present study, by using CD44, CD24, and EPCAM, we proved that cantharidin and norcantharidin eliminated the stem-like pancreatic cancer cells, making cantharidin and norcantharidin promising candidates for pancreatic cancer treatment.

$\mathrm{WNT} / \beta$-catenin signaling has a critical role in the regulation of tissue selfrenewal, especially in intestinal crypts and bone growth plates $(48,49)$. Deregulated WNT/ $\beta$-catenin signaling has been associated with CSCs activity; particularly, cutaneous CSCs require $\beta$-catenin signaling to maintain their tumorigenic phenotype (34). We previously reported that cantharidin could suppress migration and growth of pancreatic cancer cells via inhibition on the WNT/ $\beta$-catenin pathway. In the present study, we found that pretreatment of PANC-1 cells with FH535, a classical $\beta$-catenin pathway inhibitor, attenuated the repression on CD44, CD24, and EPCAM by cantharidin and norcantharidin, suggesting cantharidin and its derivate suppressed the stemness of pancreatic cancer cells via inhibition on WNT/ $\beta$-catenin pathway.

Emerging evidence has demonstrated that CSCs are resistant to conventional chemotherapy. It was found that CSCs in mouse mammary tumors contributed to cisplatin resistance (50) and that CSCs in colorectal cancers were responsible for the resistance to chemotherapeutic drugs (51). In chronic myeloid leukemia, imatinib, an Abl tyrosine kinase inhibitor, dramatically depleted differentiated cells but failed to reduce leukaemic stem cells, thus leading to disease progression (23). A previous study using biopsy tissues from patients with breast cancer showed that chemotherapy led to an increased percentage of $\mathrm{CD} 44^{+} / \mathrm{CD} 24^{+}$cells consistent with increased clone formation ability (52). Liu et al demonstrated that $\mathrm{CD}_{133}{ }^{+}$cells derived from human glioblastoma were significantly resistant to various chemotherapeutic agents compared to $\mathrm{CD} 3^{-}$cells, and CD133 expression was significantly higher in recurrent glioblastoma (23). Therefore, strategies targeting CSCs are gaining their prospect in cancer treatment.

Similar to other CSCs, the presence of pancreatic CSCs with the drug-resistant and high metastatic characteristics contributes to the treatment failure resulting in high mortality of patients diagnosed with pancreatic cancer. Gemcitabine and erlotinib are first line pharmacotherapeutics commonly used in the treatment of pancreatic cancers (17). However, the median overall survival of gemcitabine treated patients with advanced pancreatic cancer is still only 5-6 months (53). To improve the prognosis of patients, low dose gemcitabine therapy combined with radiotherapy or other chemotherapeutic agents has been used, but with few exceptions, no improvement in the overall survival rates of patients with advanced pancreatic cancer has been reported $(54,55)$. Some EGFR inhibitors (e.g., erlotinib) are approved for lung cancer, however, available data are inconclusive for treatment of pancreatic cancer 
patients with EGFR-targeted therapies (56). This unfavorable situation could be due to the presence of CSCs. Pancreatic CSCs identified by CD133 or CD44/CD24/EPCAM were more resistant to gemcitabine $(57,58)$. In a xenograft model, gemcitabine-treated animals had a decrease in tumor size but an increase in the $\mathrm{CD}_{13} 3^{+}$cells fraction (57). Hong et al found that gemcitabine treatment eliminated the bulk of cells but left a CD44 ${ }^{+}$enriched cells population and a small subset of $\mathrm{CD} 44^{+} / \mathrm{CD} 24^{+} / \mathrm{EPCAM}^{+}$cells, which was able to proliferate and reconstituted the neoplasm (23). Likewise, resistance to erlotinib has also been found to be associated with stemness of pancreatic cancer cells (59).

Therefore, strategies targeting CSCs holds promise in pharmacotherapy sensitization. For example, by using human pancreatic andenocarcinoma in nonobese diabetic/severe combined immunodeficiency (NOD/SCID) mice, an in vivo study found that the anticancer effect of gemcitabine was strengthened by XL184, an inhibitor of pancreatic CSC marker c-Met (27). In a separate report, RNA interference of CD44 inhibited the clonogenic activity of gemcitabine-resistant pancreatic cancer cells (23). As cantharidin and norcantharidin were able to eliminate pancreatic CSCs, we investigated whether cantharidin and norcantharidin could strengthen the cytotoxicity of gemcitabine and erlotinib. Although short-term exposure of cantharidin or norcantharidin with gemcitabine did not present synergistic effect, data from the long-term co-treatment was favorable. Excitingly, co-treatment of cantharidin or norcantharidin with erlotinib presented synergistic effect after both short- and long-term exposures. Thus, the present study suggested that cantharidin and norcantharidin possess the ability of eliminating pancreatic CSCs, could be promising candidates to strengthen present first line therapeutics against pancreatic cancer.

Because CSCs possess many of the features of normal stem cells, it will be important to determine if such targeting strategies may be effective in tackling CSCs without unduly harming normal stem cells. Two recent reports suggest that selective targeting of CSCs may indeed be possible. A study by Yilmaz and colleagues investigated the role of the tumor suppressor gene PTEN in leukemia (60). They found that conditional deletion of PTEN in adult hematopoietic cells in mice lead to expansion of leukemic CSCs and depletion of normal hematopoietic stem cells. Treatment of the mice with rapamycin, used to counter the effects of PTEN deletion, inhibited the development of CSCs while preserving normal stem-cell populations. In another study, targeting the CSC surface molecule CD44 using a monoclonal antibody resulted in eradication of human acute myeloid leukemic stem cells using a xenograft model in immunodeficient mice while sparing normal stem cells (61). Interestingly, it has been proven that clinical treatment with cantharidin and norcantharidin could increase the count of white cells (10), suggesting the stemness repression ability of cantharidin and its derivate could also be cancer-targeting.

In conclusion, CSCs contribute to resistance to conventional chemotherapy and radiation (22), and are believed to be the major culprits in cancer recurrence and metastasis (5). Present therapies that target rapidly dividing non-stem cell bulk populations in the tumor may produce rapid tumor shrinkage, but they are unlikely to produce long-term remissions unless the
CSCs responsible for maintaining the disease are also targeted $(62,63)$. Therefore, eradication of CSCs in the bulk tumor directly affects prognosis (64). In the present study, we proved that cantharidin and norcantharidin could repress the stemness of pancreatic cancer cells and strengthen the cytotoxicity of pharmacotherapeutics against pancreatic cancer, suggesting cantharidin and norcantharidin show promise as therapeutics against pancreatic cancer and may bring new light to the treatment of this aggressive neoplasm.

\section{Acknowledgements}

This study was supported by grants from the National Natural Science Foundation of China (nos. 81472296, 81101867, 81272542 and 81200369), the CSPAC-Celgene Foundation, the China International Medical Foundation (grant no. CIMF-F-H001-057), the Special Foundation of Clinical Medicine of Jiangsu Provincial Bureau of Science and Technology (grant no. BL2014039), the Scientific Research Project of Jiangsu Provincial Bureau of Traditional Chinese Medicine (grant no. L213236), the Medical Scientific Research Project of Jiangsu Provincial Bureau of Health (grant no. Z201206), the Special Foundation of Wu Jieping Medical Foundation for Clinical Scientific Research (grant nos. 320.6753.1225 and 320.6750.12242), the Science and Education for Health Foundation of Suzhou for Youth (grant nos. SWKQ1003 and SWKQ1011), the Science and Technology Project Foundation of Suzhou (grant nos. SYS201112, SYSD2012137 and SYS201335), the Science and Technology Foundation of Suzhou Xiangcheng (grant nos. SZXC2012-70 and XJ201451) and a Project founded by the Priority Academic Program Development of Jiangsu Higher Education Institutions.

\section{References}

1. Wang SJ, Gao Y, Chen H, Kong R, Jiang HC, Pan SH, Xue DB, Bai XW and Sun B: Dihydroartemisinin inactivates NF-kappaB and potentiates the anti-tumor effect of gemcitabine on pancreatic cancer both in vitro and in vivo. Cancer Lett 293: 99-108, 2010.

2. Li D, Xie K, Wolff R and Abbruzzese JL: Pancreatic cancer. Lancet 363: 1049-1057, 2004.

3. Guo $\mathrm{X}$ and Cui Z: Current diagnosis and treatment of pancreatic cancer in China. Pancreas 31: 13-22, 2005.

4. Bardeesy N and DePinho RA: Pancreatic cancer biology and genetics. Nat Rev Cancer 2: 897-909, 2002.

5. Bednar F and Simeone DM: Pancreatic cancer stem cell biology and its therapeutic implications. J Gastroenterol 46: 1345-1352, 2011.

6. Castellanos JA, Merchant NB and Nagathihalli NS: Emerging targets in pancreatic cancer: Epithelial-mesenchymal transition and cancer stem cells. Onco Targets Ther 6: 1261-1267, 2013.

7. Xia J, Chen C, Chen Z, Miele L, Sarkar FH and Wang Z: Targeting pancreatic cancer stem cells for cancer therapy. Biochim Biophys Acta 1826: 385-399, 2012.

8. Wang GS: Medical uses of mylabris in ancient China and recent studies. J Ethnopharmacol 26: 147-162, 1989.

9. Li W, Xie L, Chen Z, Zhu Y, Sun Y, Miao Y, Xu Z and Han X: Cantharidin, a potent and selective PP2A inhibitor, induces an oxidative stress-independent growth inhibition of pancreatic cancer cells through G2/M cell-cycle arrest and apoptosis. Cancer Sci 101: 1226-1233, 2010.

10. Li W, Chen Z, Zong Y, Gong F, Zhu Y, Zhu Y, Lv J, Zhang J, Xie L, Sun Y, et al: PP2A inhibitors induce apoptosis in pancreatic cancer cell line PANC-1 through persistent phosphorylation of IKK $\alpha$ and sustained activation of the NF- $\kappa B$ pathway. Cancer Lett 304: 117-127, 2011. 
11. Li W, Chen Z, Gong FR, Zong Y, Chen K, Li DM, Yin H, Duan WM, Miao Y, Tao M, et al: Growth of the pancreatic cancer cell line PANC-1 is inhibited by protein phosphatase $2 \mathrm{~A}$ inhibitors through overactivation of the c-Jun N-terminal kinase pathway. Eur J Cancer 47: 2654-2664, 2011.

12. Wu MY, Xie X, Xu ZK, Xie L, Chen Z, Shou LM, Gong FR, $\mathrm{Xie}$ YF, Li W and Tao M: PP2A inhibitors suppress migration and growth of PANC-1 pancreatic cancer cells through inhibition on the Wnt/ $\beta$-catenin pathway by phosphorylation and degradation of $\beta$-catenin. Oncol Rep 32: 513-522, 2014.

13. Xie X, Wu MY, Shou LM, Chen LP, Gong FR, Chen K, Li DM, Duan WM, Xie YF, Mao YX, et al: Tamoxifen enhances the anticancer effect of cantharidin and norcantharidin in pancreatic cancer cell lines through inhibition of the protein kinase $\mathrm{C}$ signaling pathway. Oncol Lett 9: 837-844, 2015.

14. Honkanen RE: Cantharidin, another natural toxin that inhibits the activity of serine/threonine protein phosphatases types 1 and 2A. FEBS Lett 330: 283-286, 1993.

15. Prakash N and Wurst W: A Wnt signal regulates stem cell fate and differentiation in vivo. Neurodegener Dis 4: 333-338, 2007.

16. Cui J, Jiang W, Wang S, Wang L and Xie K: Role of Wnt/ $\beta$-catenin signaling in drug resistance of pancreatic cancer. Curr Pharm Des 18: 2464-2471, 2012.

17. Gresham GK, Wells GA, Gill S, Cameron C and Jonker DJ: Chemotherapy regimens for advanced pancreatic cancer: A systematic review and network meta-analysis. BMC Cancer 14: $471,2014$.

18. Shou LM, Zhang QY, Li W, Xie X, Chen K, Lian L, Li ZY, Gong FR, Dai KS, Mao YX, et al: Cantharidin and norcantharidin inhibit the ability of MCF-7 cells to adhere to platelets via protein kinase $C$ pathway-dependent downregulation of $\alpha 2$ integrin. Oncol Rep 30: 1059-1066, 2013.

19. Reghunathan R, Bi C, Liu SC, Loong KT, Chung TH, Huang G and Chng WJ: Clonogenic multiple myeloma cells have shared stemness signature associated with patient survival. Oncotarget 4: 1230-1240, 2013

20. Li C, Heidt DG, Dalerba P, Burant CF, Zhang L, Adsay V, Wicha M, Clarke MF and Simeone DM: Identification of pancreatic cancer stem cells. Cancer Res 67: 1030-1037, 2007.

21. Jemal A, Siegel R, Xu J and Ward E: Cancer statistics, 2010. CA Cancer J Clin 60: 277-300, 2010.

22. Lee CJ, Li C and Simeone DM: Human pancreatic cancer stem cells: Implications for how we treat pancreatic cancer. Trans Oncol 1: 14-18, 2008.

23. Hong SP, Wen J, Bang S, Park S and Song SY: CD44-positive cells are responsible for gemcitabine resistance in pancreatic cancer cells. Int J Cancer 125: 2323-2331, 2009.

24. Reim F, Dombrowski Y, Ritter C, Buttmann M, Häusler S, Ossadnik M, Krockenberger M, Beier D, Beier CP, Dietl J, et al: Immunoselection of breast and ovarian cancer cells with trastuzumab and natural killer cells: Selective escape of CD44 high CD24 $4^{\text {low }} /$ HER2low breast cancer stem cells. Cancer Res 69 8058-8066, 2009.

25. Yabuuchi S, Pai SG, Campbell NR, de Wilde RF, De Oliveira E, Korangath P, Streppel MM, Rasheed ZA, Hidalgo M, Maitra A, et al: Notch signaling pathway targeted therapy suppresses tumor progression and metastatic spread in pancreatic cancer. Cancer Lett 335: 41-51, 2013.

26. Bonnet D and Dick JE: Human acute myeloid leukemia is organized as a hierarchy that originates from a primitive hematopoietic cell. Nat Med 3: 730-737, 1997.

27. Li C, Wu JJ, Hynes M, Dosch J, Sarkar B, Welling TH, Pasca di Magliano M and Simeone DM.: c-Met is a marker of pancreatic cancer stem cells and therapeutic target. Gastroenterology 141: 2218-2227 e2215, 2011.

28. Rasheed ZA and Matsui W: Biological and clinical relevance of stem cells in pancreatic adenocarcinoma. J Gastroenterol Hepatol 27 (Suppl 2): S15-S18, 2012.

29. Richard V, Nair MG, Santhosh Kumar TR and Pillai MR: Side population cells as prototype of chemoresistant, tumor-initiating cells. BioMed Res Int 2013: 517237, 2013.

30. Marhaba R, Klingbeil P, Nuebel T, Nazarenko I, Buechler MW and Zoeller M: CD44 and EpCAM: Cancer-initiating cell markers. Curr Mol Med 8: 784-804, 2008.

31. Naor D, Nedvetzki S, Golan I, Melnik L and Faitelson Y: CD44 in cancer. Crit Rev Clin Lab Sci 39: 527-579, 2002.

32. Jothy S: CD44 and its partners in metastasis. Clin Exp Metastasis 20: 195-201, 2003.
33. Klingbeil P, Marhaba R, Jung T, Kirmse R, Ludwig T and Zöller M: CD44 variant isoforms promote metastasis formation by a tumor cell-matrix cross-talk that supports adhesion and apoptosis resistance. Mol Cancer Res 7: 168-179, 2009.

34. Malanchi I, Peinado H, Kassen D, Hussenet T, Metzger D, Chambon P, Huber M, Hohl D, Cano A, Birchmeier W, et al: Cutaneous cancer stem cell maintenance is dependent on betacatenin signalling. Nature 452: 650-653, 2008.

35. Chong JM and Speicher DW: Determination of disulfide bond assignments and $\mathrm{N}$-glycosylation sites of the human gastrointestinal carcinoma antigen GA733-2 (CO17-1A, EGP, KS1-4, KSA and Ep-CAM). J Biol Chem 276: 5804-5813, 2001.

36. Trebak M, Begg GE, Chong JM, Kanazireva EV, Herlyn D and Speicher DW: Oligomeric state of the colon carcinomaassociated glycoprotein GA733-2 (Ep-CAM/EGP40) and its role in GA733-mediated homotypic cell-cell adhesion. J Biol Chem 276: 2299-2309, 2001

37. Mohan A, Nalini V, Mallikarjuna K, Jyotirmay B and Krishnakumar S: Expression of motility-related protein MRP1/ CD9, N-cadherin, E-cadherin, alpha-catenin and beta-catenin in retinoblastoma. Exp Eye Res 84: 781-789, 2007.

38. Yamashita T, Budhu A, Forgues M and Wang XW: Activation of hepatic stem cell marker EpCAM by Wnt-beta-catenin signaling in hepatocellular carcinoma. Cancer Res 67: 10831-10839, 2007.

39. Guillemot JC, Naspetti M, Malergue F, Montcourrier P, Galland F and Naquet P: Ep-CAM transfection in thymic epithelial cell lines triggers the formation of dynamic actin-rich protrusions involved in the organization of epithelial cell layers. Histochem Cell Biol 116: 371-378, 2001.

40. Münz M, Kieu C, Mack B, Schmitt B, Zeidler R and Gires O: The carcinoma-associated antigen EpCAM upregulates c-myc and induces cell proliferation. Oncogene 23: 5748-5758, 2004.

41. Osta WA, Chen Y, Mikhitarian K, Mitas M, Salem M, Hannun YA, Cole DJ and Gillanders WE: EpCAM is overexpressed in breast cancer and is a potential target for breast cancer gene therapy. Cancer Res 64: 5818-5824, 2004.

42. Baeuerle PA and Gires O: EpCAM (CD326) finding its role in cancer. Br J Cancer 96: 417-423, 2007.

43. Oonishi K, Cui X, Hirakawa H,, Fujimori A, Kamijo T, Yamada S, Yokosuka O and Kamada T: Different effects of carbon ion beams and X-rays on clonogenic survival and DNA repair in human pancreatic cancer stem-like cells. Radiother Oncol 105: 258-265, 2012

44. Ohara Y, Oda T, Sugano M, Hashimoto S, Enomoto T, Yamada K, Akashi Y, Miyamoto R, Kobayashi A, Fukunaga K, et al: Histological and prognostic importance of CD44(+)/CD24(+) / EpCAM(+) expression in clinical pancreatic cancer. Cancer Sci 104: 1127-1134, 2013.

45. Herreros-Villanueva M, Zubia-Olascoaga A and Bujanda L: c-Met in pancreatic cancer stem cells: Therapeutic implications. World J Gastroenterol 18: 5321-5323, 2012.

46. Rasheed ZA, Yang J, Wang Q, Kowalski J, Freed I, Murter C, Hong SM, Koorstra JB, Rajeshkumar NV, He X, et al: Prognostic significance of tumorigenic cells with mesenchymal features in pancreatic adenocarcinoma. J Natl Cancer Inst 102: 340-351, 2010.

47. Ding Q, Miyazaki Y, Tsukasa K, Matsubara S, Yoshimitsu M and Takao S: CD133 facilitates epithelial-mesenchymal transition through interaction with the ERK pathway in pancreatic cancer metastasis. Mol Cancer 13: 15, 2014

48. Clevers H: Wnt/beta-catenin signaling in development and disease. Cell 127: 469-480, 2006.

49. Andrade AC, Nilsson O, Barnes KM and Baron J: Wnt gene expression in the post-natal growth plate: Regulation with chondrocyte differentiation. Bone 40: 1361-1369, 2007.

50. Shafee N, Smith CR, Wei S, Kim Y, Mills GB, Hortobagyi GN, Stanbridge EJ and Lee EY: Cancer stem cells contribute to cisplatin resistance in Brca1/p53-mediated mouse mammary tumors. Cancer Res 68: 3243-3250, 2008.

51. Todaro M, Alea MP, Di Stefano AB, Cammareri P, Vermeulen L, Iovino F, Tripodo C, Russo A, Gulotta G, Medema JP, et al: Colon cancer stem cells dictate tumor growth and resist cell death by production of interleukin-4. Cell Stem Cell 1: 389-402, 2007.

52. Li X, Lewis MT, Huang J, Gutierrez C, Osborne CK, Wu MF, Hilsenbeck SG, Pavlick A, Zhang X, Chamness GC, et al: Intrinsic resistance of tumorigenic breast cancer cells to chemotherapy. J Natl Cancer Inst 100: 672-679, 2008.

53. Jemal A, Siegel R, Ward E, Murray T, Xu J and Thun MJ: Cancer statistics, 2007. CA Cancer J Clin 57: 43-66, 2007. 
54. Ciliberto D, Botta C, Correale P, Rossi M, Caraglia M, Tassone P and Tagliaferri P: Role of gemcitabine-based combination therapy in the management of advanced pancreatic cancer: A meta-analysis of randomised trials. Eur J Cancer 49: 593-603, 2013.

55. Ko AH, Dito E, Schillinger B, Venook AP, Xu Z, Bergsland EK, Wong D, Scott J, Hwang J and Tempero MA: A phase II study evaluating bevacizumab in combination with fixed-dose rate gemcitabine and low-dose cisplatin for metastatic pancreatic cancer: Is an anti-VEGF strategy still applicable? Invest New Drugs 26: 463-471, 2008.

56. Nedaeinia R, Avan A, Manian M, Salehi R and GhayourMobarhan M: EGFR as a potential target for the treatment of pancreatic cancer: Dilemma and controversies. Curr Drug Targets 15: 1293-1301, 2014.

57. Hermann PC, Huber SL, Herrler T, Aicher A, Ellwart JW, Guba M, Bruns CJ and Heeschen C: Distinct populations of cancer stem cells determine tumor growth and metastatic activity in human pancreatic cancer. Cell Stem Cell 1: 313-323, 2007 .

58. Lee CJ, Dosch J and Simeone DM: Pancreatic cancer stem cells. J Clin Oncol 26: 2806-2812, 2008.
59. Seguin L, Kato S, Franovic A, Camargo MF, Lesperance J, Elliott KC, Yebra M, Mielgo A, Lowy AM, Husain H, et al: An integrin 33 -KRAS-RalB complex drives tumour stemness and resistance to EGFR inhibition. Nat Cell Biol 16: 457-468, 2014.

60. Yilmaz OH, Valdez R, Theisen BK, Guo W, Ferguson DO, Wu H and Morrison SJ: Pten dependence distinguishes haematopoietic stem cells from leukaemia-initiating cells. Nature 441: 475-482, 2006.

61. Jin L, Hope KJ, Zhai Q, Smadja-Joffe F and Dick JE: Targeting of CD44 eradicates human acute myeloid leukemic stem cells. Nat Med 12: 1167-1174, 2006

62. Jones RJ, Matsui WH and Smith BD: Cancer stem cells: Are we missing the target? J Natl Cancer Inst 96: 583-585, 2004.

63. Gupta PB, Onder TT, Jiang G, Tao K, Kuperwasser C, Weinberg RA and Lander ES: Identification of selective inhibitors of cancer stem cells by high-throughput screening. Cell 138: 645-659, 2009.

64. Dingli D and Michor F: Successful therapy must eradicate cancer stem cells. Stem Cells 24: 2603-2610, 2006. 